\title{
Redox-modulatory vitamins and minerals that prospectively predict mortality in older British people: the National Diet and Nutrition Survey of people aged 65 years and over
}

\author{
Christopher J. Bates ${ }^{1 *}$, Mark Hamer ${ }^{2}$ and Gita D. Mishra ${ }^{2}$ \\ ${ }^{1}$ MRC Human Nutrition Research, Elsie Widdowson Laboratory, Fulbourn Road, Cambridge CB1 9NL, UK \\ ${ }^{2}$ Department of Epidemiology and Public Health, University College, London WC1E 6BT, UK
}

(Received 19 January 2010 - Revised 11 June 2010 - Accepted 5 July 2010 - First published online 1 September 2010)

\section{Abstract}

The predictive power, for total, vascular, cancer and respiratory mortality, of selected redox-modulatory (vitamin and mineral nutrient) indices measured at baseline, was studied in the British National Diet and Nutrition Survey (community-living subset) of people aged 65 years and over. Mortality status and its primary and underlying causes were recorded for 1054 (mean age 76.6 (SD 7.4) years and $49.0 \%$ female) participants, from the baseline survey in 1994-5 until September 2008. During this interval, $74 \%$ of the male and $62 \%$ of the female participants died. Total mortality was significantly predicted by baseline plasma concentrations (per sD) of vitamin C (hazard ratio (HR) 0.81; 95\% CI 0.74, 0.88), $\alpha$-carotene (HR 0.90; 95\% CI 0.81, 0.99), Se (HR 0.76; 95\% CI 0.69, 0.84), Zn (HR 0.79; $95 \%$ CI $0 \cdot 72,0 \cdot 87), \mathrm{Cu}(\mathrm{HR} 1 \cdot 27 ; 95 \%$ CI $1 \cdot 14,1.42)$ and Fe (HR $0.81 ; 95 \%$ CI $0.74,0.89)$. Total mortality was also significantly predicted by baseline dietary intakes (per SD) of food energy (HR 0.86; $95 \%$ CI $0 \cdot 79,0 \cdot 94$ ), vitamin C (HR 0.88; 95\% CI 0.80, 0.94), carotenoids (HR 0.89; $95 \%$ CI 0.83, 0.96), Zn (HR 0.89; $95 \%$ CI 0.82, 0.96) and Cu (HR 0.91; $95 \%$ CI 0.84, 1.00). Prediction patterns and significance for primary vascular, cancer and respiratory mortality differed in certain respects, but not fundamentally. Model adjustment for known disease or mortality risk predictors resulted in loss of significance for some of the indices; however, plasma Se and Zn, and food energy remained significant predictors. We conclude that total and primary vascular, cancer and respiratory mortality in older British people of both sexes is predicted by several biochemical indices of redox-modulatory nutrients, some of which may reflect the respondents' acute-phase status at baseline, whereas others may reflect the healthiness of their lifestyle.

Key words: British National Survey of Older Adults: Mortality prediction: Intakes and biochemical indices: Plasma vitamins C and $\mathrm{E}$, carotenoids, selenium, zinc, copper and iron

Relationships between biochemical status indices and later morbidity and mortality experience can help to predict causal relationships, and thereby to clarify certain physiological and pathological mechanisms that may be related to important disease risk factors in ageing humans. In the present study, we have focused on mortality outcomes of the community-living participants from the countrywide British National Diet and Nutrition Survey of people aged 65 years and over, for which the fieldwork was performed in $1994-5^{(1)}$. Subsequent mortality outcomes were available from the National Health Service register of deaths, up to September 2008. The purpose of the present paper is to explore the predictive significance of a selection of biochemical indices for nutrients that are believed to mediate redox-modulatory (antioxidant or pro-oxidant) functions in living tissues, all of which were measured as part of the original population surveillance protocol. Evidence that subsequent all-cause mortality may be predicted by vitamin $C$ intakes and/or status has been obtained in several previous studies ${ }^{(2-10)}$, and similarly for carotene ${ }^{(11,12)}$ and $\mathrm{Se}^{(12-14)}$.

In addition to the modulation of redox status, several nutrient indices are known to be modified by, and hence to reflect, acute-phase status, and hence, potentially, to reflect mortality risk (since chronic inflammatory states frequently underlie those disease processes that lead ultimately to death $\left.{ }^{(15)}\right)$. Also, the same vitamins and minerals that modulate redox status may, in many cases, also modulate key immune functions ${ }^{(16-18)}$. As well as the practical usefulness of status indices as predictors of future mortality, a key question is whether the observed links between baseline nutrient status and future mortality are likely to be driven by (potentially correctable) nutritional

Abbreviation: ICD, International Classification of Diseases.

*Corresponding author: Dr C. J. Bates, email chris.bates@mrc-hnr.cam.ac.uk 
imbalances, or by the more intractable processes of inflammatory response to chronic disease?

\section{Subjects and methods}

The survey procedures have been described in detail elsewhere $^{(1)}$; therefore only a brief summary is given here. At baseline, in 1994-5, two separate population samples were randomly selected: one from communityliving people aged 65 years and over and the other from long-stay institutions. Only the community-living sample has been included in the present study. Participants were drawn from eighty randomly selected postcode sectors in mainland Britain and allocated to four sequential 3-month fieldwork 'waves' corresponding to the four seasons, beginning in October 1994. Demographic, socioeconomic and other information was obtained by a trained interviewer in the participant's home. A $4 \mathrm{~d}$ weighed dietary record was also obtained by the interviewer, and anthropometric indices, blood pressure and pulse rate, and after separate consent, a fasting early morning venous blood sample were taken by a trained nurse. The blood sample was subdivided and used for a wide range of analyses. Of these, the assays that are relevant to the present study were as follows: (a) fluorometric assay based on the reaction of dehydroascorbic acid with ortho-phenylenediamine (checked for validity against a HPLC assay and against quality assurance standards with assigned values, provided by the US National Institute of Standards and Technology) for plasma (total) vitamin C; (b) liquid chromatographic assay for plasma retinol, $\alpha$ - and $\gamma$-tocopherols and carotenoids; (c) colorimetric assays for plasma $\mathrm{Zn}, \mathrm{Cu}, \mathrm{Fe}$ and $\mathrm{Fe} \%$ saturation of transferrin; (d) an antibody-based nephelometric assay for plasma $\alpha_{1}$-antichymotrypsin; (e) an inductively coupled plasma MS assay for plasma Se. In-house quality assessments and inter-laboratory exchanges were undertaken in order to monitor the accuracy and stability of the assays. Plasma $\alpha_{1}$-antichymotrypsin was selected as a medium-duration plasma acute-phase indicator, which tends to remain raised during chronic inflammatory states. Between-run quality-control sample CV were all $\leq 11 \%$, and the mean quality-control CV was $5 \cdot 7 \%$.

The study was conducted according to the guidelines laid down in the Declaration of Helsinki, and all procedures involving human subjects were approved by the Local Research Ethics Committees representing each of the eighty postcode sectors used. The protocol was also approved by the Ethical Committee of the MRC Dunn Nutrition Unit (of which the Micronutrient Status Laboratory is now part of MRC Human Nutrition Research), in Cambridge. Written informed consent was obtained from all the subjects.

The present study included 1054 participants, comprising 538 men and 516 women, with partial or complete data available for the analyses of interest here, all of whom agreed to be flagged on the National Register of Births and Deaths, and whose status (i.e. as still alive or registered as having died) was known in September 2008. No exclusions, other than those resulting from willingness to participate or the availability of blood samples, were imposed, and there was no evidence for sampling bias. Because of missing values (principally due to incomplete consent availability for the blood sampling), the analyses of the blood biomarker variables are typically based on a subset of approximately 800 participants.

\section{Statistical analysis}

Cox proportional hazards models were used, with years of survival as the time scale, to estimate the risk of mortality (all-cause and vascular disease) according to each biochemical and nutritional index. The data were censored to September 2008 in those participants who had survived. The proportional hazards assumption was examined by comparing the cumulative hazard plots, grouped as exposure, wherein no appreciable violations were observed. We used standardised values ( $z$-scores) for each of the explanatory variables examined, which have the advantage of expressing the hazard ratios per standard deviation, rather than per measurement unit, thereby achieving an enhanced conformity between the disparate indices. Vascular disease mortality was defined according to International Classification of Diseases versions 9 (ICD-9: 390-459) and 10 (ICD-10: I01-I99). Cancer mortality was defined according to ICD-9: 140-239 and ICD-10: C00-D48. Respiratory disease mortality was defined according to ICD-9: 460-519 and ICD-10: J00-J99, and all of the above were limited to the primary cause of death.

In the multivariate models, adjustment was made for potential confounders, including age and sex in all models. Since we were only interested in relationships between indices, rather than estimates of prevalence, we did not apply the weighting factors that were used in the data analyses for the Survey Report ${ }^{(1)}$. All tests of statistical significance were based on two-sided probability, and $P<0.05$ was deemed significant throughout.

\section{Results}

Of the community-living survey participants who gave consent for follow-up flagging of the National Health Service Register of deaths, and who had provided at least one index value reported in this follow-up study, 94.5\% could be accounted for by known deaths and known survivors. As noted previously in the Subjects and methods section, the blood biomarker analyses are confined to the subset of the participants who provided a blood sample, comprising approximately 800 participants.

Table 1 provides mean and median baseline values, subdivided by sex, for the indices explored in this report. 
Table 1. Summary of selected status indices and nutrient intakes in the survey respondents who are included in the present study ( $n$ 1054)

(Mean values and standard deviations; median and range values)

\begin{tabular}{|c|c|c|c|c|c|c|c|c|c|c|}
\hline & \multicolumn{5}{|c|}{ Male } & \multicolumn{5}{|c|}{ Female } \\
\hline & $n^{\star}$ & Mean & SD & Median & Range & $n^{\star}$ & Mean & SD & Median & Range \\
\hline Age (years) & 538 & $75 \cdot 8$ & $6 \cdot 9$ & $75 \cdot 0$ & $65-96$ & 516 & $77 \cdot 3$ & $7 \cdot 9$ & $76 \cdot 0$ & $65-99$ \\
\hline Body wt (kg) & 532 & $75 \cdot 2$ & $12 \cdot 2$ & $74 \cdot 6$ & $38 \cdot 7-121$ & 509 & $64 \cdot 0$ & $12 \cdot 7$ & $63 \cdot 3$ & $32 \cdot 5-112 \cdot 9$ \\
\hline $\mathrm{Ht}(\mathrm{m})$ & 528 & 1.69 & 0.07 & 1.69 & $1.49-1.98$ & 503 & 1.55 & 0.07 & 1.55 & $1 \cdot 20-1 \cdot 75$ \\
\hline BMI $\left(\mathrm{kg} / \mathrm{m}^{2}\right)$ & 527 & $26 \cdot 3$ & $3 \cdot 7$ & $26 \cdot 1$ & $16 \cdot 3-43 \cdot 2$ & 502 & $26 \cdot 6$ & $4 \cdot 8$ & $26 \cdot 2$ & $14 \cdot 4-44 \cdot 6$ \\
\hline \multicolumn{11}{|l|}{ Biochemical indices } \\
\hline Plasma vitamin $\mathrm{C}(\mu \mathrm{mol} / \mathrm{l})$ & 442 & $38 \cdot 2$ & $22 \cdot 6$ & $38 \cdot 6$ & $<3-101.5$ & 410 & $45 \cdot 8$ & $26 \cdot 1$ & $48 \cdot 2$ & $<3-116.5$ \\
\hline Plasma vitamin A $(\mu \mathrm{mol} / \mathrm{l})$ & 409 & $2 \cdot 21$ & 0.58 & $2 \cdot 15$ & $0.85-5.55$ & 390 & $2 \cdot 18$ & 0.66 & 2.09 & $0.42-6 \cdot 8$ \\
\hline Plasma $\alpha$-tocopherol $(\mu \mathrm{mol} / \mathrm{l})$ & 409 & $35 \cdot 0$ & $9 \cdot 9$ & $34 \cdot 2$ & $0.45-7.49$ & 390 & $39 \cdot 1$ & $12 \cdot 4$ & 37.5 & $10 \cdot 3-128 \cdot 0$ \\
\hline Plasma $\gamma$-tocopherol ( $\mu \mathrm{mol} / \mathrm{l})$ & 407 & $2 \cdot 24$ & 1.06 & $2 \cdot 07$ & $0.45-7.49$ & 385 & 2.53 & $1 \cdot 20$ & $2 \cdot 31$ & $0.57-8.65$ \\
\hline Plasma $\alpha$-carotene $(\mathrm{nmol} / \mathrm{l})$ & 403 & $64 \cdot 0$ & $64 \cdot 0$ & $51 \cdot 0$ & $5 \cdot 0-84 \cdot 8$ & 385 & $79 \cdot 5$ & $84 \cdot 4$ & $55 \cdot 0$ & $4 \cdot 0-88 \cdot 8$ \\
\hline Plasma $\beta$-carotene (nmol/l) & 408 & 323 & 225 & 273 & $8-1674$ & 390 & 405 & 261 & 349 & $37-1960$ \\
\hline Plasma $\beta$-cryptoxanthin (nmol/l) & 399 & 117 & 121 & 77 & $3-866$ & 389 & 151 & 165 & 98 & $4-1265$ \\
\hline Plasma lutein + zeaxanthin $(\mathrm{nmol} / \mathrm{l})$ & 409 & 378 & 179 & 340 & $99-1583$ & 390 & 389 & 212 & 352 & $66-2189$ \\
\hline Plasma lycopene (nmol/l) & 408 & 268 & 184 & 238 & $12-1015$ & 389 & 274 & 209 & 225 & $8-1262$ \\
\hline Plasma Se $(\mu \mathrm{mol} / \mathrm{l})$ & 428 & 95 & 218 & 962 & $375-2376$ & 398 & 924 & 211 & 925 & $461-1786$ \\
\hline $\begin{array}{l}\text { Blood glutathione peroxidase } \\
\text { (nmol NADPH/mg Hb per min) }\end{array}$ & 412 & 140 & 34 & 133 & $59-359$ & 369 & 145 & 37 & 13 & $85-353$ \\
\hline Plasma Zn $(\mu \mathrm{mol} / \mathrm{l})$ & 377 & $14 \cdot 2$ & $2 \cdot 1$ & $14 \cdot 1$ & $7 \cdot 2-20 \cdot 5$ & 364 & $14 \cdot 2$ & 2.4 & $14 \cdot 0$ & $8 \cdot 2-24 \cdot 2$ \\
\hline Plasma Cu ( $\mu \mathrm{mol} / \mathrm{l})$ & 376 & $17 \cdot 4$ & $3 \cdot 0$ & $17 \cdot 0$ & $10 \cdot 4-31 \cdot 5$ & 362 & $19 \cdot 5$ & 3.9 & $19 \cdot 3$ & $8 \cdot 4-38 \cdot 0$ \\
\hline Plasma Fe $(\mu \mathrm{mol} / \mathrm{l})$ & 438 & $13 \cdot 7$ & $4 \cdot 9$ & $13 \cdot 0$ & $2 \cdot 8-37 \cdot 4$ & 412 & $12 \cdot 0$ & $4 \cdot 4$ & 11.9 & $2 \cdot 2-32 \cdot 3$ \\
\hline Plasma Fe \% saturation (\%) & 437 & $28 \cdot 1$ & $11 \cdot 1$ & $26 \cdot 7$ & $4 \cdot 1-91 \cdot 2$ & 412 & $24 \cdot 2$ & $10 \cdot 3$ & 23.5 & $4 \cdot 0-82 \cdot 7$ \\
\hline Plasma $\alpha_{1}$-antichymotrypsin $(\mathrm{g} / \mathrm{l})$ & 430 & $0 \cdot 38$ & 0.094 & 0.365 & $0 \cdot 16-1 \cdot 14$ & 408 & 0.39 & 0.089 & 0.385 & $0 \cdot 22-1 \cdot 01$ \\
\hline \multicolumn{11}{|l|}{ Estimated average daily dietary intakes } \\
\hline Energy (MJ) & 538 & 7.95 & 1.94 & 7.95 & $3 \cdot 44-17 \cdot 3$ & 516 & 5.95 & 1.42 & $5 \cdot 88$ & $1.91-9.77$ \\
\hline Vitamin C (mg) & 538 & $71 \cdot 1$ & $70 \cdot 5$ & $59 \cdot 0$ & $4.9-1023$ & 516 & 65.4 & $57 \cdot 1$ & $49 \cdot 0$ & $1 \cdot 0-601$ \\
\hline Vitamin A (retinol) (mg) & 538 & 0.94 & $1 \cdot 76$ & 0.45 & $<0.01-20.4$ & 516 & 0.85 & 1.56 & 0.39 & $0.06-18 \cdot 8$ \\
\hline Vitamin E (mg) & 538 & 9.51 & $8 \cdot 18$ & $7 \cdot 80$ & $0.8-114$ & 516 & $10 \cdot 69$ & 39.4 & 6.09 & $0.06-18.8$ \\
\hline Total carotenoids (mg) & 538 & 1.97 & 1.55 & $1 \cdot 62$ & $0 \cdot 10-12 \cdot 0$ & 516 & 1.62 & 1.40 & $1 \cdot 12$ & $0.06-9.97$ \\
\hline $\mathrm{Zn}(\mathrm{mg})$ & 538 & $8 \cdot 81$ & $2 \cdot 86$ & $8 \cdot 50$ & $1 \cdot 86-27 \cdot 1$ & 516 & 6.96 & $2 \cdot 56$ & $6 \cdot 52$ & $1 \cdot 65-23 \cdot 3$ \\
\hline $\mathrm{Cu}(\mathrm{mg})$ & 538 & $1 \cdot 10$ & 0.68 & 0.97 & $0.29-6.72$ & 516 & 0.88 & 0.55 & 0.77 & $0.19-5.87$ \\
\hline Non-haem Fe (mg) & 538 & 11.4 & $10 \cdot 3$ & $10 \cdot 0$ & $1 \cdot 7-174 \cdot 2$ & 516 & $10 \cdot 9$ & $18 \cdot 4$ & $7 \cdot 9$ & $2 \cdot 3-201 \cdot 5$ \\
\hline Haem Fe (mg) & 538 & 0.72 & 0.57 & 0.59 & $0.00-4.83$ & 516 & 0.53 & 0.45 & 0.42 & $0.00-4.80$ \\
\hline
\end{tabular}

* The values for $n$ in Table 1 and the maximum values for $n$ in Tables 2 and 3 are limited to the numbers definitely known to have died or to have been still alive at the time of the follow-up analysis, i.e. they excluded those (approximately $5 \%$ of the original participants) who were lost to follow-up. Where individual index values of $n$ are lower in Tables 2 and 3 , it was because of missing values, since not all of the respondents provided blood (or sufficient blood) for every one of the assays or calculations ${ }^{(1)}$.

The original Survey Report $^{(1)}$ provided baseline index values for all of the original survey participants, together with further details about the aims of the selection procedures and the methodologies used.

Table 2 shows the age- and sex-adjusted hazard ratios for all-cause and primary vascular disease-cause mortality. Significant predictors of all-cause mortality were as follows: plasma vitamin $\mathrm{C}, \alpha$-carotene, lutein + zeaxanthin, Se, $\mathrm{Zn}$, $\mathrm{Cu}, \mathrm{Fe}$ (and the \% saturation of its carrier, Fe-binding protein or transferrin); plasma $\alpha_{1}$-antichymotrypsin, and dietary intakes of energy, vitamin $\mathrm{C}$, carotenoids, $\mathrm{Zn}$ and $\mathrm{Cu}$. With the exception of plasma $\mathrm{Cu}$ and $\alpha_{1}$-antichymotrypsin, all of the significant mortality predictors had hazard ratios below $1 \cdot 0$, which signifies reduced risk. $\alpha_{1}$-Antichymotrypsin concentrations are known to increase during inflammatory states, and hence the association of increased concentrations with increased risk, i.e. hazard ratios greater than 1.0. The major Cu-containing plasma protein, caeruloplasmin, like $\alpha_{1}$-antichymotrypsin, also increases during inflammatory states, which probably explains the observed association of increased concentrations with increased risk. Serum ferritin (not shown) was not a significant predictor of mortality, either for allcause or for the three subcategories of mortality risk considered here. Likewise, neither $\alpha$-tocopherol nor $\gamma$-tocopherol became significant predictors, for all-cause, vascular disease or cancer mortality, even when adjusted for plasma (total) cholesterol (not shown). Intakes of food energy, vitamin $\mathrm{C}$, total carotenoids, $\mathrm{Zn}$ and $\mathrm{Cu}$ were significant predictors of mortality, with increased intakes being associated with longer survival for each of these nutrients (Table 2). If food energy was included in the model (not shown), then vitamin $\mathrm{C}$ and carotenoid intakes still retained their prediction significance $(P=0.003$ and 0.046 , respectively), whereas the other nutrient intakes shown in Table 2 lost their significance $(P>0.05)$.

When subdivided by sex (not shown), the predictive power of the biochemical status indices was similar for both men and women, with the exception of plasma $\mathrm{Cu}$, which was significant only for men (hazard ratio 1.60 (95\% CI 1.35, 1.90) ( $P \leq 0.001)$ ) compared with women (hazard ratio $1.06(95 \% \mathrm{CI} 0.93,1 \cdot 22)(P=0 \cdot 4))$. The predictive power of nutrient intakes was significant $(P<0.05)$ 
for men for food energy, vitamins $C$ and E, carotenoids, $\mathrm{Zn}$ and $\mathrm{Cu}$, but was NS for women, for any of these nutrient intakes. After adjustment for food energy, intakes of vitamin $\mathrm{C}$ and carotenoids remained significant for men ( $P=0.03$ for both).

For primary vascular disease mortality, comprising approximately $26 \%$ of all mortality, the significant predictors were similar to those for all-cause mortality; however, plasma $\alpha$-carotene, lutein + zeaxanthin and dietary energy, and intakes of carotenoids and $\mathrm{Cu}$ failed to achieve significance at the $5 \%$ probability level here.

For primary cancer mortality, comprising approximately $20 \%$ of all mortality, the significant biochemical index predictors were similar to those for all-cause mortality, with the exceptions that plasma lutein + zeaxanthin, $\mathrm{Cu}$ and $\alpha_{1^{-}}$ antichymotrypsin were NS. Here, the only dietary intakes that were significant were those of vitamins $\mathrm{C}$ and $\mathrm{E}$.

For primary respiratory disease mortality, comprising approximately $16 \%$ of all mortality, the significant biochemical index predictors were similar to those for allcause mortality, with the exception that plasma $\alpha$-carotene, $\mathrm{Cu}, \mathrm{Fe}$ and $\alpha_{1}$-antichymotrypsin were NS, but lycopene became marginally significant. The only dietary intake to achieve significance here was that of total carotenoids.

When subdivided both by sex and by primary cause of mortality (not shown), the most striking sex differences again arose with respect to plasma $\mathrm{Cu}$, which was a significant predictor of primary vascular disease or cancer or respiratory disease mortality, for males only, but not for females. Dietary intake of vitamin E was a significant predictor of cancer and respiratory disease mortality in males but not in females, and dietary intake of carotenoids was a significant predictor of respiratory disease mortality in males but not in females. However, in contrast to previous studies which have described significant mortality prediction by low serum or plasma vitamin C concentrations in men but not in women ${ }^{(2,6-8)}$, the present study found similar strengths of mortality prediction by plasma vitamin $\mathrm{C}$ in both men and women.

About $19 \%$ of the study respondents were regularly taking dietary supplements that contained vitamin and/or mineral components, at baseline. However, subsequent mortality was not significantly predicted by the supplemental intakes of any of the above-mentioned vitamins or minerals, and the mortality prediction patterns were similar in the $(81 \%)$ non-supplement users, to those of the entire cohort (not shown).

Exclusion of those respondents (approximately 7\%) who died in less than 2 years after the baseline fieldwork made little difference to any of the index predictions of mortality (not shown); therefore the observed patterns of mortality prediction appear not to have been

Table 2. Age- and sex-adjusted risk for the biochemical and nutritional indices, for all-cause and primary vascular disease mortality ${ }^{\star}$ (Hazard ratios and $95 \%$ confidence intervals)

\begin{tabular}{|c|c|c|c|c|c|c|}
\hline & \multicolumn{3}{|c|}{ All-cause mortality: died $n 717$, alive $n 337$} & \multicolumn{3}{|c|}{ Vascular disease mortality: died $n 189$, alive $n 337^{*}$} \\
\hline & $\begin{array}{c}\text { Age- and sex-adjusted } \\
\text { hazard ratios }\end{array}$ & $95 \% \mathrm{Cl}$ & $P$ & $\begin{array}{c}\text { Age- and sex-adjusted } \\
\text { hazard ratios }\end{array}$ & $95 \% \mathrm{Cl}$ & $P$ \\
\hline \multicolumn{7}{|l|}{ Biochemical indices (per SD) } \\
\hline Plasma vitamin $C(\mu \mathrm{mol} / /)$ & 0.81 & $0.74,0.88$ & $<0.001$ & 0.83 & $0.71,0.98$ & 0.02 \\
\hline Plasma vitamin $A(\mu \mathrm{mol} / \mathrm{l})$ & 0.96 & $0.87,1.06$ & 0.4 & 1.01 & $0.84,1 \cdot 21$ & 0.9 \\
\hline Plasma $\alpha$-tocopherol $(\mu \mathrm{mol} / \mathrm{l})$ & 0.96 & $0.87,1.06$ & 0.4 & 1.07 & $0.90,1.29$ & 0.4 \\
\hline Plasma $\gamma$-tocopherol $(\mu \mathrm{mol} / \mathrm{l})$ & 0.96 & $0.87,1.05$ & 0.3 & 0.91 & $0.75,1 \cdot 11$ & 0.4 \\
\hline Plasma $\alpha$-carotene $(\mathrm{nmol} / \mathrm{l})$ & 0.90 & $0.81,0.99$ & 0.04 & 1.01 & $0.85,1.20$ & 0.9 \\
\hline Plasma $\beta$-carotene (nmol/l) & 0.92 & $0.84,1.01$ & 0.08 & 0.96 & $0.81,1 \cdot 15$ & 0.7 \\
\hline Plasma $\beta$-cryptoxanthin $(\mathrm{nmol} / \mathrm{l})$ & 0.91 & $0.83,1.01$ & 0.07 & 1.04 & $0.86,1.26$ & 0.7 \\
\hline Plasma lutein + zeaxanthin $(\mathrm{nmol} / \mathrm{l})$ & 0.91 & $0.83,1.00$ & 0.04 & 0.90 & $0.75,1.08$ & 0.3 \\
\hline Plasma lycopene (nmol/l) & 0.92 & $0.84,1.01$ & 0.09 & 0.86 & $0.71,1.05$ & 0.15 \\
\hline Plasma Se $(\mu \mathrm{mol} / \mathrm{l})$ & 0.76 & $0.69,0.84$ & $<0.001$ & 0.73 & $0.61,0.87$ & 0.001 \\
\hline $\begin{array}{l}\text { Blood glutathione peroxidase } \\
\text { (nmol NADPH/mg Hb per min) }\end{array}$ & 0.94 & $0.85,1.03$ & $0 \cdot 2$ & $1 \cdot 00$ & $0 \cdot 84,1 \cdot 20$ & $1 \cdot 0$ \\
\hline Plasma Zn $(\mu \mathrm{mol} / \mathrm{l})$ & 0.79 & $0.72,0.87$ & $<0.001$ & 0.73 & $0.61,0.88$ & 0.001 \\
\hline Plasma Cu $(\mu \mathrm{mol} / \mathrm{l})$ & 1.27 & $1.14,1.42$ & $<0.001$ & 1.35 & $1 \cdot 12,1.63$ & 0.002 \\
\hline Plasma Fe $(\mu \mathrm{mol} / \mathrm{l})$ & 0.81 & $0.74,0.89$ & $<0.001$ & 0.79 & $0.67,0.94$ & 0.008 \\
\hline Plasma Fe \% saturation (\%) & 0.84 & $0.76,0.92$ & $<0.001$ & 0.79 & $0.67,0.94$ & 0.009 \\
\hline Plasma $\alpha_{1}$-antichymotrypsin $(\mathrm{g} / \mathrm{l})$ & $1 \cdot 22$ & $1.14,1.32$ & $<0.001$ & $1 \cdot 12$ & $1.05,1.35$ & 0.005 \\
\hline \multicolumn{7}{|l|}{ Daily dietary intakes (per SD) } \\
\hline Energy (MJ) & 0.86 & $0.79,0.94$ & 0.001 & 0.83 & $0.70,1.00$ & 0.05 \\
\hline Vitamin C (mg) & 0.88 & $0.80,0.97$ & 0.008 & 0.93 & $0.81,1.08$ & 0.4 \\
\hline Vitamin A (mg) & 1.00 & $0.93,1.07$ & $1 \cdot 0$ & 0.95 & $0.82,1 \cdot 10$ & 0.5 \\
\hline Vitamin $\mathrm{E}(\mathrm{mg})$ & 1.00 & $0.93,1.08$ & 0.9 & 1.06 & $0.90,1.23$ & 0.5 \\
\hline Total carotenoids (mg) & 0.89 & $0.82,0.96$ & 0.003 & 0.95 & $0.83,1 \cdot 10$ & 0.5 \\
\hline $\mathrm{Zn}(\mathrm{mg})$ & 0.89 & $0.82,0.96$ & 0.003 & 0.84 & $0.71,0.99$ & 0.04 \\
\hline $\mathrm{Cu}(\mathrm{mg})$ & 0.91 & $0.84,1.00$ & 0.04 & 0.92 & $0.78,1.10$ & 0.4 \\
\hline Non-haem Fe (mg) & 1.03 & $0.94,1.13$ & 0.5 & 1.06 & $0.94,1.20$ & 0.4 \\
\hline Haem Fe $(\mathrm{mg})$ & 1.03 & $0.97,1.10$ & 0.3 & 0.93 & $0.82,1.07$ & 0.3 \\
\hline
\end{tabular}

*As explained in the legend to Table 1, these were the study maximum values for $n$; the actual values for each index were the same as shown in Table 1 . 
Table 3. Age- and sex-adjusted risk for the biochemical and nutritional indices for primary cancer and primary respiratory disease mortality ${ }^{*}$ (Hazard ratios and $95 \%$ confidence intervals)

\begin{tabular}{|c|c|c|c|c|c|c|}
\hline & \multicolumn{3}{|c|}{ Cancer mortality: died $n$ 140, alive $n 337$} & \multicolumn{3}{|c|}{ Respiratory disease mortality: died $n 112$, alive $n 337^{\star}$} \\
\hline & $\begin{array}{l}\text { Age- and sex-adjusted } \\
\text { hazard ratios }\end{array}$ & $95 \% \mathrm{Cl}$ & $P$ & $\begin{array}{c}\text { Age- and sex-adjusted } \\
\text { hazard ratios }\end{array}$ & $95 \% \mathrm{Cl}$ & $P$ \\
\hline \multicolumn{7}{|l|}{ Biochemical indices (per SD) } \\
\hline Plasma vitamin C ( $\mu \mathrm{mol} / \mathrm{l})$ & 0.81 & $0.66,0.99$ & 0.035 & 0.78 & $0.63,0.96$ & 0.02 \\
\hline Plasma vitamin A ( $\mu \mathrm{mol} / \mathrm{l})$ & 0.90 & $0.73,1.12$ & 0.4 & 0.88 & $0 \cdot 70,1 \cdot 11$ & 0.3 \\
\hline Plasma $\alpha$-tocopherol $(\mu \mathrm{mol} / \mathrm{l})$ & 0.96 & $0.87,1.06$ & 0.4 & 0.76 & $0.60,0.96$ & 0.02 \\
\hline Plasma $\gamma$-tocopherol ( $\mu \mathrm{mol} / \mathrm{l})$ & 0.89 & $0.71,1 \cdot 13$ & 0.3 & 0.84 & $0.65,1.08$ & 0.2 \\
\hline Plasma $\alpha$-carotene $(\mathrm{nmol} / \mathrm{l})$ & 0.67 & $0.47,0.96$ & 0.03 & 0.94 & $0 \cdot 75,1 \cdot 18$ & 0.6 \\
\hline Plasma $\beta$-carotene $(\mathrm{nmol} / \mathrm{l})$ & 0.87 & $0.69,1 \cdot 10$ & $0 \cdot 25$ & 0.84 & $0.67,1.05$ & 0.13 \\
\hline Plasma $\beta$-cryptoxanthin (nmol/l) & 0.86 & $0.66,1.13$ & 0.3 & 0.80 & $0.58,1.09$ & 0.16 \\
\hline Plasma lutein+zeaxanthin $(\mathrm{nmol} / \mathrm{l})$ & $1 \cdot 06$ & $0.87,1.30$ & 0.5 & 0.77 & $0.60,0.99$ & 0.04 \\
\hline Plasma lycopene (nmol/l) & 1.06 & $0.87,1.30$ & 0.5 & 0.77 & $0.59,1.00$ & 0.05 \\
\hline Plasma Se $(\mu \mathrm{mol} / \mathrm{l})$ & 0.72 & $0.58,0.89$ & 0.002 & 0.65 & $0.51,0.82$ & $<0.001$ \\
\hline $\begin{array}{l}\text { Blood glutathione peroxidase } \\
\text { (nmol NADPH/mg Hb per min) }\end{array}$ & $1 \cdot 00$ & $0 \cdot 81,1 \cdot 23$ & $1 \cdot 0$ & 0.83 & $0.65,1.05$ & $0 \cdot 12$ \\
\hline Plasma Zn $(\mu \mathrm{mol} / \mathrm{l})$ & 0.69 & $0.55,0.86$ & 0.001 & 0.79 & $0.62,0.99$ & 0.04 \\
\hline Plasma Cu $(\mu \mathrm{mol} / \mathrm{l})$ & $1 \cdot 18$ & $0.92,1.49$ & $0 \cdot 2$ & $1 \cdot 12$ & $0.89,1.41$ & 0.3 \\
\hline Plasma Fe $(\mu \mathrm{mol} / \mathrm{l})$ & 0.73 & $0.59,0.89$ & 0.002 & 0.83 & $0.66,1.04$ & 0.11 \\
\hline Plasma Fe \% saturation (\%) & 0.72 & $0.58,0.89$ & 0.002 & 0.93 & $0 \cdot 74,1 \cdot 16$ & 0.5 \\
\hline Plasma $\alpha_{1}$-antichymotrypsin $(\mathrm{g} / \mathrm{l})$ & 1.08 & $0.91,1.27$ & 0.4 & $1 \cdot 15$ & $0.98,1.36$ & 0.09 \\
\hline \multicolumn{7}{|l|}{ Daily dietary intakes (per SD) } \\
\hline Energy (kJ) & 0.82 & $0.67,1.01$ & 0.06 & 0.85 & $0.66,1.08$ & $0 \cdot 2$ \\
\hline Vitamin C (mg) & 0.73 & $0.57,0.94$ & 0.015 & 0.81 & $0.62,1.05$ & 0.11 \\
\hline Vitamin A (mg) & 1.03 & $0.88,1.019$ & 0.7 & 0.87 & $0.70,1.09$ & 0.2 \\
\hline Vitamin E (mg) & $0 \cdot 13$ & $0.04,0.42$ & 0.001 & 0.32 & $0.10,1.08$ & 0.07 \\
\hline Total carotenoids (mg) & 0.92 & $0 \cdot 77,1 \cdot 10$ & 0.3 & 0.74 & $0.59,0.93$ & 0.01 \\
\hline $\mathrm{Zn}(\mathrm{mg})$ & 0.86 & $0.71,1.04$ & 0.11 & 0.88 & $0.70,1.09$ & 0.2 \\
\hline $\mathrm{Cu}(\mathrm{mg})$ & 0.87 & $0.71,1.04$ & 0.2 & 0.96 & $0 \cdot 78,1 \cdot 18$ & 0.7 \\
\hline Non-haem Fe (mg) & 1.05 & $0.93,1.18$ & 0.4 & 0.97 & $0.79,1.27$ & $1 \cdot 0$ \\
\hline Haem Fe (mg) & $1 \cdot 18$ & $1.03,1.35$ & 0.014 & 0.96 & $0 \cdot 80,1 \cdot 15$ & 0.7 \\
\hline
\end{tabular}

${ }^{*}$ As explained in the legend to Table 1, these were the study maximum values for $n$; the actual values for each index were the same as shown in Table 1 .

disproportionately affected by early deaths, and hence by the effects of serious illness on appetite or status indices at baseline.

Tables 4-7 show which of the nutrient indices survive into multivariate models: part (a) in each table contains just age, sex, and each single status and dietary indices that were found to be significant as shown in Tables 2 and 3; part (b) contains all of the significantly predictive nutrient variables plus age and sex, followed by removal of those which then became non-significant in the multivariate model; part (c) contains these same indices, plus five further 'risk' indices that were measured at baseline, namely: $\alpha_{1}$-antichymotrypsin (acute-phase status indicator), plasma creatinine (renal status indicator), plasma total and HDL-cholesterol concentrations (traditional vascular disease risk indicators), plasma albumin concentration (frailty indicator); and finally part (d) also contains BMI, systolic blood pressure, current smoking index, number of prescribed drugs being taken, self-reported health score, physical activity score and receipt (or not) of certain state benefits (a potential index of relative poverty). For all-cause mortality (Table 4), only the mineral status indices (for $\mathrm{Se}, \mathrm{Zn}, \mathrm{Cu}$ and $\mathrm{Fe}$ ) plus dietary energy remained significant in the partly adjusted multivariate model (b), with only plasma Se, Zn and dietary energy surviving to the fully adjusted model (d). In Tables 5 and 6, somewhat similar patterns were observed for primary vascular and primary cancer mortality; however, for the latter (alone), haem Fe was a significant predictor, and indeed, became progressively more significant in the more fully adjusted multivariate models. Dietary vitamin E (but not dietary energy) was significant for cancer mortality. From Table 7 , it can be observed that only plasma $\alpha$-tocopherol and dietary carotenoids were significant predictors for respiratory disease mortality. It can be observed from Tables 4-7 that for some of the nutritional variables and mortality types, there was a steady progression towards decreasing significance of mortality prediction in the more fully adjusted models, whereas for other nutritional variables and mortality types, the prediction significance either stayed essentially the same or even increased in the more fully adjusted models.

\section{Discussion}

Because the predictive value of conventional risk factors for disease and mortality appears to diminish with advancing age ${ }^{(19)}$, recent attention has focused on the discriminative ability of novel risk markers in elderly cohorts ${ }^{(20)}$. The purpose of the present paper is to explore the predictive significance of a subset of the biochemical status indices and nutrient intakes that were measured at baseline as 
Table 4. Multivariate hazard ratios for nutritional indices and intakes for all-cause mortality (Hazard ratios and $95 \%$ confidence intervals)

\begin{tabular}{|c|c|c|c|c|c|c|}
\hline & Hazard ratios (per SD) & $95 \% \mathrm{Cl}$ & $P$ & Hazard ratios (per SD) & $95 \% \mathrm{Cl}$ & $P$ \\
\hline & \multicolumn{3}{|c|}{ Model (a): died $n 717$, alive $n 357^{\star}$} & \multicolumn{3}{|c|}{ Model (b): died $n$ 482, alive $n 242$} \\
\hline Plasma Se $(\mu \mathrm{mol} / \mathrm{l})$ & 0.76 & $0.69,0.84$ & $<0.001$ & 0.82 & $0.73,0.91$ & $<0.001$ \\
\hline Plasma Zn ( $\mu \mathrm{mol} / \mathrm{l})$ & 0.79 & $0.72,0.87$ & $<0.001$ & 0.84 & $0.76,0.93$ & 0.001 \\
\hline Plasma Cu $(\mu \mathrm{mol} / \mathrm{l})$ & $1 \cdot 27$ & $1.14,1.42$ & $<0.001$ & $1 \cdot 20$ & $1.07,1.34$ & 0.002 \\
\hline Plasma Fe $(\mu \mathrm{mol} / \mathrm{l})$ & 0.81 & $0.74,0.89$ & $<0.001$ & 0.87 & $0.78,0.96$ & 0.005 \\
\hline \multirow[t]{2}{*}{ Dietary energy $(\mathrm{MJ} / \mathrm{d})$} & $0 \cdot 86$ & $0.79,0.94$ & 0.001 & 0.86 & $0.77,0.96$ & 0.007 \\
\hline & \multicolumn{3}{|c|}{ Model (c): died $n$ 472, alive $n 241$} & \multicolumn{3}{|c|}{ Model (d): died $n$ 403, alive $n 226$} \\
\hline Plasma Se $(\mu \mathrm{mol} / \mathrm{l})$ & 0.82 & $0.74,0.92$ & 0.001 & 0.83 & $0.73,0.94$ & 0.004 \\
\hline Plasma Zn ( $\mu \mathrm{mol} / \mathrm{l})$ & 0.88 & $0.79,0.98$ & 0.017 & 0.86 & $0.76,0.97$ & 0.017 \\
\hline Plasma Cu $(\mu \mathrm{mol} / \mathrm{l})$ & 1.08 & $0.94,1.22$ & 0.3 & 1.02 & $0.88,1.18$ & 0.8 \\
\hline Plasma Fe $(\mu \mathrm{mol} / \mathrm{l})$ & 0.87 & $0.78,0.96$ & 0.005 & 0.94 & $0.84,1.05$ & 0.3 \\
\hline Dietary energy $(\mathrm{MJ} / \mathrm{d})$ & 0.87 & $0.77,0.98$ & 0.027 & 0.87 & $0.77,0.98$ & 0.03 \\
\hline
\end{tabular}

${ }^{*}$ As explained in the legend to Table 1, these were the study maximum values for $n$ (i.e. those for the dietary variables); the values for the biochemical indices were lower, see Table 1. These models, for all-cause mortality, follow on from the left-hand data column in Table 2. For the calculations in part (a), each single (nutrient) variable was entered into the Cox proportional hazards model, together with age and sex (as in Tables 2 and 3 ). For those in part (b), all of the significant $(P<0.05)$ vitamin or mineral predictor variables from Table 3 , plus age and sex, were initially included together in the model; then those which fell below the assigned $P<0.05$ significance cut-off were successively removed, yielding just the significantly predictive nutrient variables in this multivariate model. For the calculations for the models in part (c), the significantly predictive vitamin or mineral indices or intakes from model (b) were further adjusted by the inclusion of $\alpha_{1}$-antichymotrypsin (an acute-phase indicator), plasma creatinine (a renal status indicator), plasma total and HDL-cholesterol concentrations and plasma albumin concentration. For the calculations in model (d), BMI, systolic blood pressure, current smoking index, number of prescribed drugs being taken, self-reported health score, physical activity score and receipt (or not) of certain state benefits (as an index of poverty) were further added to the variables in model (c).

part of the original population surveillance protocol of the National Diet and Nutrition Survey of People Aged 65 Years and Over, with a specific focus on those nutrients that are known to modulate redox status in living tissues.

Important strengths of the present study are that, as far as possible, the population sample was chosen as being statistically representative of the community-living people of mainland Britain in 1994-5. A wide range of nutrition-related factors was measured at baseline, including questionnaire-derived socio-demographic information, a $4 \mathrm{~d}$ weighed diet estimate, anthropometric measurements, haematology, blood and urine biochemistry (including a large number of nutritional indices), dental assessment, etc., and the follow-up period for mortality outcomes was substantial, i.e. 13-14 years. One inevitable weakness, invariably associated with any cross-sectional national survey, was the fact that the baseline measures were sampled at a single time-point only. It was thus, in principle, unable to address the issues of long-term causal pathways, or of intervening events occurring after the baseline measures. Another weakness was that cost considerations and database limitations precluded the inclusion of some potentially desirable indices: for instance, Se intakes could not be calculated at baseline because British food Se contents were not sufficiently well established. Nevertheless, the National Diet and Nutrition Survey series has probably included more relevant biochemical and nutrient intake indices than most population surveys except the National Health and Nutrition Examination Surveys (NHANES) of North America.

In the present study, both the status indices and the nutrient intakes which significantly predicted early mortality appeared to be driven by basic dietary nutrient concentrations rather than by dietary supplements. Our conclusions from Tables 2-5, that plasma concentrations of vitamin C, certain carotenoids and Se can be significant

Table 5. Multivariate hazard ratios for nutritional indices and intakes for vascular mortality*

(Hazard ratios and $95 \%$ confidence intervals)

\begin{tabular}{|c|c|c|c|c|c|c|}
\hline & Hazard ratios (per SD) & $95 \% \mathrm{Cl}$ & $P$ & Hazard ratios (per SD) & $95 \% \mathrm{Cl}$ & $P$ \\
\hline & \multicolumn{3}{|c|}{ Model (a): died $n 189$, alive $n 337$} & \multicolumn{3}{|c|}{ Model (b): died $n$ 129, alive $n 242$} \\
\hline Plasma Se $(\mu \mathrm{mol} / \mathrm{l})$ & 0.73 & $0.61,0.87$ & 0.001 & 0.77 & $0.64,0.94$ & 0.01 \\
\hline Plasma Zn $(\mu \mathrm{mol} / \mathrm{l})$ & 0.73 & $0.61,0.88$ & 0.001 & 0.77 & $0.63,0.93$ & 0.008 \\
\hline Plasma Cu $(\mu \mathrm{mol} / \mathrm{l})$ & 1.35 & $1.12,1.63$ & 0.002 & 1.33 & $1 \cdot 10,1 \cdot 60$ & 0.002 \\
\hline \multirow[t]{2}{*}{ Dietary energy (MJ/d) } & 0.83 & $0.70,1.00$ & 0.05 & $0 \cdot 79$ & $0.64,0.98$ & 0.03 \\
\hline & \multicolumn{3}{|c|}{ Model (c): died $n$ 125, alive $n 241$} & \multicolumn{3}{|c|}{ Model (d): died $n$ 105, alive $n 226$} \\
\hline Plasma Se $(\mu \mathrm{mol} / \mathrm{l})$ & 0.81 & $0.66,0.99$ & 0.04 & 0.84 & $0.67,1.06$ & 0.14 \\
\hline Plasma Zn ( $\mu \mathrm{mol} / \mathrm{l})$ & $0 \cdot 81$ & $0.66,1.00$ & 0.05 & $0 \cdot 83$ & $0.65,1.07$ & 0.15 \\
\hline Plasma Cu $(\mu \mathrm{mol} / \mathrm{l})$ & $1 \cdot 19$ & $0.96,1.47$ & 0.12 & 1.02 & $0.80,1.30$ & 0.9 \\
\hline Dietary energy $(\mathrm{MJ} / \mathrm{d})$ & 0.75 & $0.60,0.94$ & 0.014 & 0.83 & $0.64,1.07$ & 0.16 \\
\hline
\end{tabular}

\footnotetext{
* Please see the legend to Table 4 for an explanation of the four models, which follow on from the data, for primary vascular disease mortality, in the
} right-hand data column in Table 2. 
Table 6. Multivariate hazard ratios for nutritional indices and intakes for cancer mortality* (Hazard ratios and $95 \%$ confidence intervals)

\begin{tabular}{|c|c|c|c|c|c|c|}
\hline & Hazard ratios (per SD) & $95 \% \mathrm{Cl}$ & $P$ & Hazard ratios (per SD) & $95 \% \mathrm{Cl}$ & $P$ \\
\hline & \multicolumn{3}{|c|}{ Model (a): died $n$ 140, alive $n 337$} & \multicolumn{3}{|c|}{ Model (b): died $n$ 92, alive $n 243$} \\
\hline Plasma Se $(\mu \mathrm{mol} / \mathrm{l})$ & 0.72 & $0.58,0.89$ & 0.002 & 0.79 & $0.63,0.99$ & 0.04 \\
\hline Plasma Zn $(\mu \mathrm{mol} / \mathrm{l})$ & 0.69 & $0.55,0.86$ & 0.001 & 0.70 & $0.56,0.88$ & 0.002 \\
\hline Dietary vitamin $\mathrm{E}(\mathrm{mg} / \mathrm{d})$ & 0.13 & $0.04,0.42$ & 0.001 & 0.23 & $0.06,0.84$ & 0.026 \\
\hline & \multicolumn{3}{|c|}{ Model (c): died $n$ 90, alive $n 242$} & \multicolumn{3}{|c|}{ Model (d): died $n$ 87, alive $n 227$} \\
\hline Plasma Se $(\mu \mathrm{mol} / \mathrm{l})$ & 0.76 & $0.60,0.96$ & 0.024 & 0.78 & $0.60,1.01$ & 0.06 \\
\hline Plasma Zn $(\mu \mathrm{mol} / \mathrm{l})$ & 0.74 & $0.58,0.95$ & 0.019 & 0.74 & $0.57,0.96$ & 0.03 \\
\hline Dietary vitamin $\mathrm{E}(\mathrm{mg} / \mathrm{d})$ & $0 \cdot 16$ & $0.04,0.65$ & 0.011 & 0.19 & $0.04,0.81$ & 0.025 \\
\hline
\end{tabular}

* If haem $\mathrm{Fe}$ is added to these models of cancer mortality, it is a significant predictor, higher values being associated with greater cancer mortality, as follows: Model 1, 1.18 (1.03, 1.35) (0.014); Model 2, 1.15 (0.99, 1.34) (0.06); Model 3: 1.27 (1.08, 1.49) (0.003); Model 4: 1.26 (1.06, 1.50) (0.008). Please see the legend to Table 4 for an explanation of the four models, which follow on from the data, for primary cancer mortality, in the left-hand data column in Table 3.

predictors of subsequent all-cause or cardiovascular or cancer mortality in older adults, are in agreement with several other studies in Western countries during the past two decades ${ }^{(2-14,21-24)}$. Both plasma vitamin $\mathrm{C}$ and Se also predicted mortality from primary vascular, cancer and respiratory mortality; however, the predictive power of individual plasma carotenoids was more variable, between these subcategories of mortality risk. Se prediction (but not that of vitamin C) persisted into six of the eight multivariate models as shown in Tables 4 and 5, thus appearing to be, perhaps surprisingly, robust. (The fact that blood glutathione peroxidase, another putative index of Se status, failed to predict mortality in any of the models tested may be due to the fact that this enzyme only reflects Se status in situations of relative Se deficiency ${ }^{(25)}$, and indeed, the correlation between plasma Se and blood glutathione peroxidase was comparatively weak in the population studied ${ }^{(26)}$.) Recent research on Se in human nutrition has suggested a wide range of possible interactions with disease processes, including some important protective effects ${ }^{(16,27)}$. A study based on the Third National Health and Nutrition Examination Survey in the USA ${ }^{(28)}$ found a non-linear association between serum Se concentration and all-cause or cancer mortality. The range of plasma Se concentrations found in the British National Diet and Nutrition Survey was generally lower than that of the US study, and included only very few (approximately 1\%) that fell into the region of high Se concentrations that predicted shorter survival in the US study; therefore our conclusion that higher baseline Se concentrations are predictive of longer survival in Britain is entirely consistent with the observations of the US study.

Plasma $\alpha$-tocopherol, which was not a significant predictor for all-cause mortality, became significant for respiratory mortality as shown in Tables 3 and 5, and somewhat surprisingly, vitamin E intake became significant (only) for cancer mortality as shown in these same two tables; carotenoid intake becoming significant (only) for respiratory disease mortality as shown in these two tables. The observation that plasma vitamin $\mathrm{E}$ differed fundamentally from the estimated vitamin $\mathrm{E}$ intake in its mortality prediction capacity seems unsurprising in view of the relative weakness of the inter-index correlation between these two indices (only approximately $1.6 \%$ of the variance of plasma $\alpha$-tocopherol was explained by the variation in vitamin E intake, based on Pearson's correlation). All of the vitamins studied plus Se (with regard to its role at the active catalytic centre of the glutathione peroxidase enzymes) are considered to be primarily antioxidant (and hence protective) in vivo, although several of them can also exhibit pro-oxidant (i.e. possibly deleterious) properties ${ }^{(29-32)}$. Dietary supplements of some carotenoids, in particular, have been associated with an increased risk of some degenerative diseases ${ }^{(33,34)}$, and a recent meta-analysis ${ }^{(35)}$ has found consistent evidence

Table 7. Multivariate hazard ratios for nutritional indices and intakes for respiratory disease mortality*

(Hazard ratios and $95 \%$ confidence intervals)

\begin{tabular}{|c|c|c|c|c|c|c|}
\hline & Hazard ratios (per SD) & $95 \% \mathrm{Cl}$ & $P$ & Hazard ratios (per SD) & $95 \% \mathrm{Cl}$ & $P$ \\
\hline & \multicolumn{3}{|c|}{ Model (a): died $n$ 482, alive $n 242$} & \multicolumn{3}{|c|}{ Model (b): died $n$ 129, alive $n 242$} \\
\hline Plasma $\alpha$-tocopherol ( $\mu \mathrm{mol} / \mathrm{l})$ & 0.76 & $0.60,0.96$ & 0.02 & 0.77 & $0.60,0.98$ & 0.03 \\
\hline \multirow[t]{2}{*}{ Carotenoids intake $(\mathrm{mg} / \mathrm{d})$} & 0.74 & $0.59,0.96$ & 0.01 & 0.72 & $0.56,0.91$ & 0.008 \\
\hline & \multicolumn{3}{|c|}{ Model (c): died $n$ 407, alive $n 227$} & \multicolumn{3}{|c|}{ Model (d): died $n$ 123, alive $n 259$} \\
\hline Plasma $\alpha$-tocopherol ( $\mu \mathrm{mol} / \mathrm{l})$ & 0.80 & $0.63,1.01$ & 0.06 & 0.87 & $0.67,1.14$ & 0.3 \\
\hline Carotenoids intake $(\mathrm{mg} / \mathrm{d})$ & 0.77 & $0.57,1.04$ & 0.09 & 0.86 & $0.62,1.19$ & 0.4 \\
\hline
\end{tabular}

* Please see the legend to Table 4 for an explanation of the four models, which follow on from the data, for primary respiratory disease mortality, in the righthand data column in Table 3. 
for deleterious effects, on all-cause mortality, for dietary supplements containing vitamins $\mathrm{A}, \mathrm{E}$ and/or $\beta$-carotene.

Less well studied, however, is the relationship of the mineral nutrient indices plasma $\mathrm{Zn}$ and $\mathrm{Fe}$, as potential predictors of future mortality. Tables $2-5$ suggest that, in the present study, these were all comparatively robust predictors, not only of all-cause-mortality but also of two of the three subcategories of primary mortality from vascular diseases and cancer, while plasma $\mathrm{Zn}$ also predicted mortality from primary respiratory disease. Whereas $\mathrm{Zn}$ is generally considered to be 'antioxidant' and therefore protective in vivo ${ }^{(36,37)}$, which may, in turn, be linked to its well-established immunoprotective functions ${ }^{(17,38)}$, in redox-modulatory terms, the opposite is true for $\mathrm{Fe}$, which often exerts pro-oxidant potential. However, Fe is, of course, an essential nutrient, and Fe deficiency is one of the commonest recognised mineral deficiency disease in human populations. Since in the present study, both $\mathrm{Zn}$ and Fe were associated with reduced mortality risk, it appears unlikely that their redox-modulatory properties are dominant here. Deficiency effects (on mortality) seem likewise unlikely, although possible. More probable, however, is their relationship with debility and risk of mortality through their relationship with chronic inflammation and the acute-phase reaction. Both plasma $\mathrm{Zn}$ and plasma $\mathrm{Fe}$ (or the $\mathrm{Fe} \%$ saturation of Fe-binding transferrin) are negative acute-phase reactants and were associated with reduced mortality risk here. Plasma $\mathrm{Cu}$, like plasma $\alpha_{1}$-antichymotrypsin, is a positive acute-phase reactant, and both of these indices were associated with increased risk of all-cause and primary vascular disease mortality (Table 2). Neither index, however, significantly predicted primary cancer or respiratory disease mortality (Table 3), suggesting that these two status indices may tend to change in parallel with each other. In this context, vascular disease is usually considered to be a long-term chronic condition, possibly characterised by an inflammatory state at baseline, whereas death from respiratory disease may more often arise from acute infections near the end of life (e.g. bronchitis, pleurisy, etc.), which might be one of the reasons why plasma $\alpha_{1}$-antichymotrypsin and $\mathrm{Cu}$ were significant predictors of vascular disease mortality but not of respiratory disease (or cancer) mortality here. As observed from Table 4 , when $\alpha_{1}$-antichymotrypsin was introduced as part of a suite of adjuster indices (i.e. Table 4 part (b) $v$. part (a)), plasma Cu lost its significance for the prediction for all-cause and vascular disease mortality; however, this was not necessarily true for plasma Zn or Se (Tables 4 and 5).

The pattern of significant nutrient intake predictors in the present study seems, in some respects, to be predictable, but in others it is somewhat surprising. The fact that (increased) energy intake predicted (reduced) mortality in three of the models as shown in Tables 2 and 4 may simply reflect the fact that a robust appetite reflects relatively sound health at baseline. Prediction by intakes of vitamins $\mathrm{C}$ and $\mathrm{E}$ and carotenoids as shown in Tables 2, 3 and 5 may reflect 'healthy lifestyles', including 'healthy' food choices, and factors such as healthy dental status and ability to chew fruit and other rich sources of these and related nutrients, including vitamin $\mathrm{E}$ and certain minerals ${ }^{(39)}$. The observed relationship between higher haem Fe intakes and higher risk of mortality attributed to cancer (in Table 3) seems consistent with the prevalent view that certain categories of meat intake may represent a risk factor for incidence of some cancers, especially bowel cancer.

The fact that only dietary energy survived as a significant predictor in the fully adjusted models as shown in Tables 4 and 5 may reflect the fact that many nutrient intakes are strongly correlated with energy intakes; however, the survival of dietary vitamin E (cancer mortality) and carotenoids (respiratory disease) in the absence of significance for dietary energy may imply a special significance for these nutrients in these diseases, and thus deserves future investigation. It is well known that variable misreporting of dietary intakes is a major unresolved problem for the interpretation of all surveys that include the estimation of nutrient intakes. Our survey sought to minimise this problem by the use of robust $4 \mathrm{~d}$ diet estimates based on weighed food intakes; furthermore, any measurement error present would result in attenuation of the observed relationships rather than the strengthening of relationships. However, we acknowledge that some uncertainty remains in this respect. In the present study, energy intake was found to be a significant predictor of mortality when standardised values were used, but it failed to reach conventional significance when its values were not standardised. In contrast, the key biochemical (status) indices all remained significant predictors of mortality, whether or not they were standardised.

From Tables $4-7$, it is clear that whereas the prediction significance of some of the nutritional indices was progressively attenuated after additional variables were included in the multivariate models, in other instances there was a little change, or even an increase in significance. Such variations may help to assess the relative robustness of mortality prediction, by the different (e.g. nutrient) variables, and for the different mortality categories.

In conclusion, a number of baseline nutrient status indices with 'redox-modulatory' connotations appear to predict all-cause, primary vascular disease, cancer or respiratory disease mortality in older British adults. Of these, plasma $\mathrm{Se}, \mathrm{Zn}$ and $\mathrm{Fe}$ appeared to be especially robust, with plasma vitamins $\mathrm{C}, \mathrm{E}$ and carotenoids being predictive in some, but not all, of the models examined. Some of the status indices (especially plasma $\mathrm{Cu}$ ) appeared to reflect acute-phase status; others (including dietary intakes of certain nutrients) may have reflected the robustness of appetites and dentition, and 'healthiness' of lifestyles (see Khaw et $\left.a l .{ }^{(40)}\right)$. Future studies should attempt to determine, first, which nutrients are the most frequent predictors 
of all-cause and specific-cause mortality in different populations, and second, whether these predictions can imply causal relationships, such that dietary or other interventions might promote disease-free longevity.

\section{Acknowledgements}

The survey was commissioned jointly by the Department of Health and the Ministry of Agriculture, Fisheries and Food, whose survey responsibility has since been transferred to the Food Standards Agency. It was carried out by the National Centre for Social Research, formerly Social and Community Planning Research in conjunction with the Micronutrient Status Laboratory of the MRC Dunn Nutrition Unit, now part of MRC Human Nutrition Research. The survey datasets were obtained from the survey commissioners, the University of Essex Data Archive and the Social Survey Division of the Office for National Statistics. We are indebted to Dr H. Trevor Delves and staff of the Trace Element Unit of the University of Southampton for the Se analyses and to Claire Deverill and Marie Sanchez (National Centre for Social Research) for their assistance in obtaining the mortality data. All the three authors were active in the data analysis, its interpretation and in preparing the manuscript, and in addition, G. D. M. advised on, and interpreted, the statistical analyses. There were no conflicts of interest. Funding was provided by the Medical Research Council. C. J. B. coordinated the dataset, drafted and submitted the manuscript and contributed to the data analysis; M. H. and G. D. M. contributed to the data analysis and helped to revise the manuscript.

\section{References}

1. Finch S, Doyle W, Lowe C, et al. (1998) National Diet and Nutrition Survey: People Aged 65 Years or Over. vol. 1: Report of the Diet and Nutrition Survey. London: The Stationery Office. http://www.data-archive.ac.uk/doc/4036 \%5Cmrdoc\%5Cpdf\%5Ca4036ueb.pdf.

2. Enstrom JE, Kanim LE \& Klein MA (1992) Vitamin C intake and mortality among a sample of the United States population. Epidemiology 3, 194-202.

3. Pandey DK, Shekelle R \& Selwyn BJ (1995) Dietary vitamin C and beta-carotene and risk of death in middle-aged men. The Western Electric Study. Am J Epidemiol 142, 1269-1278.

4. Sahyoun NR, Jacques PF \& Russell RM (1996) Carotenoids, vitamin $\mathrm{C}$ and $\mathrm{E}$, and mortality in an elderly population. Am J Epidemiol 144, 501-511.

5. Kromhout D, Bloemberg B, Feskens E, et al. (2000) Saturated fat, vitamin $\mathrm{C}$ and smoking predict long-term population all-cause mortality rates in the Seven Countries Study. Int J Epidemiol 29, 260-265.

6. Loria CM, Klag MJ, Caulfield LE, et al. (2000) Vitamin C status and mortality in US adults. Am J Clin Nutr 72, 139-145.

7. Khaw K-T, Bingham S, Welch A, et al. (2001) Relation between plasma ascorbic acid and mortality in men and women in EPIC-Norfolk prospective study: a prospective population study. Lancet 357, 657-663.
8. Simon JA, Hudes ES \& Tice JA (2001) Relation of serum ascorbic acid to mortality among US adults. Am J Clin Nutr 20, 255-263.

9. Fletcher AE, Breeze E \& Shetty PS (2003) Antioxidant vitamins and mortality in older persons: findings from the nutrition add-on study to the Medical Research Council Trial of Assessment and Management of Older people in the Community. Am J Clin Nutr 78, 999-1010.

10. Jia X, Aucott LS \& McNeill G (2007) Nutritional status and subsequent all-cause mortality in men and women aged 75 years or over living in the community. Br J Nutr 98, 593-599.

11. Buijsse B, Feskens EJM, Schlettwein-Gsell D, et al. (2005) Plasma carotene and alpha-tocopherol in relation to $10-y$ all-cause and cause-specific mortality in European elderly: the Survey in Europe on Nutrition and the Elderly, a Concerted Action (SENECA). Am J Clin Nutr 82, 879-886.

12. Ray AL, Semba RD, Walston J, et al. (2006) Low serum selenium and total carotenoids predict mortality among older women living in the community: the Women's Health and Aging Studies. J Nutr 136, 172-176.

13. Akrabaraly NT, Arnaud J, Hininger-Favier I, et al. (2005) Selenium and mortality in the elderly: results from the EVA study. Clin Chem 51, 2117-2123.

14. Gonzalez S, Huerta JM, Fernandez S, et al. (2007) Homocysteine increases the risk of mortality in elderly individuals. $\mathrm{BrJ}$ Nutr 97, 1138-1143.

15. Kistorp C, Raymond I, Pedersen F, et al. (2005) N-terminal pro-brain natriuretic peptide, C-reactive protein, and urinary albumin levels as predictors of mortality and cardiovascular events in older adults. JAMA 293, 1609-1616.

16. Rayman MP (2000) The importance of selenium to human health. Lancet 356, 33-241.

17. Prasad AS (2007) Zinc: mechanisms of host defense. J Nutr 37, 1345-1349.

18. Webb AL \& Villamor E (2007) Update: effects of antioxidant and non-antioxidant vitamin supplementation on immune function. Nutr Rev 65, 181-217.

19. Kannel WB (2002) Coronary heart disease risk factors in the elderly. Am J Geriatr Cardiol 11, 101-107.

20. de Ruijter W, Westendorp RGJ, Assendelft WJJ, et al. (2009) Use of Framingham risk score and new biomarkers to predict cardiovascular mortality in older people: population based observational cohort study. BMJ 338, a3083.

21. Buijsse B, Feskens EJM, Kwape L, et al. (2008) Both alphaand beta-carotene but not tocopherols and vitamin $\mathrm{C}$, are inversely related to 15 -year cardiovascular mortality in Dutch elderly men. J Nutr 138, 344-350.

22. Kok FJ, de Bruijn AM, Vermeeren R, et al. (1987) Serum selenium, vitamin antioxidants, and cardiovascular mortality: a 9-year follow-up study an The Netherlands. Am J Clin Nutr 45, $462-468$.

23. Wei W-Q, Abnet CC, Qiao Y-L, et al. (2004) Prospective study of serum selenium concentrations and esophageal and gastric cardia cancer, heart disease, stroke, and total death. Am J Clin Nutr 79, 80-85.

24. Gale CR, Martyn CN, Winter PD, et al. (1995) Vitamin C and risk of death from stroke and coronary heart disease in a cohort of elderly people. BMJ 310, 1563-1566.

25. Thomson C \& Robinson M (1996) The changing selenium status of New Zealand residents. Eur J Clin Nutr 50, 107-114.

26. Bates CJ, Thane CW, Prentice A, et al. (2002) Selenium status and its correlates in a British National Diet and Nutrition Survey: people aged 65 years and over. J Trace Elem Med Biol 16, 1-8. 
27. Rayman MP (2008) Food chain selenium and human health: emphasis on intake. Br J Nutr 100, 238-253.

28. Bleys J, Navas-Acien A \& Guallar E (2008) Serum selenium levels and all-cause, cancer and cardiovascular mortality among US adults. Arch Intern Med 168, 404-410.

29. Podmore ID, Griffiths HR, Herbert KE, et al. (1998) Vitamin C exhibits pro-oxidant properties. Lancet 392, 559.

30. Halliwell B (1996) Commentary. Oxidative stress, nutrition and health. Experimental strategies for optimization of nutritional antioxidant intake in humans. Free Radic Res 25, 57-74.

31. Ricciarelli R, Zingg J-M \& Azzi A (2001) Vitamin E: protective role of a Janus molecule. FASEB J 15, 2314-2325.

32. Cooke MS, Evans MD, Mistry N, et al. (2002) Role of dietary antioxidants in the prevention of in vivo oxidative DNA damage. Nutr Res Rev 15, 19-41.

33. Daly S, Mills J, Molloy AM, et al. (1997) Minimum effective dose of folic acid for food fortification to prevent neuraltube defects. Lancet 350, 1666-1669.

34. Vivekananthan DP, Penn MS, Sapp SK, et al. (2003) Use of antioxidant vitamins for the prevention of cardiovascular disease: meta-analysis of randomised trials. Lancet 361 , 2017-2023

35. Bjelakovik G, Nikolova D, Gluud LL, et al. (2008) Mortality in randomized trials of antioxidant supplements for primary and secondary prevention. JAMA 297, 842-857.

36. Bray TM \& Bettger WJ (1990) The physiological role of zinc as antioxidant. Free Radic Biol Med 8, 281-291.

37. DiSilvestro RA (2000) Zinc in relation to diabetes and oxidative stress. J Nutr 130, Suppl. 5S, 1509S-1511S.

38. Walker CF \& Black RE (2004) Zinc and the risk for infectious disease. Annu Rev Nutr 24, 255-275.

39. Steele JG, Sheiham A, Marcenes W, et al. (1998) National Diet and Nutrition Survey: People Aged 65 Years and Over. vol. 2: Report of the Oral Health Survey. London: The Stationery Office.

40. Khaw K-T, Wareham N, Bingham S, et al. (2008) Combined impact of health behaviours and mortality in men and women: the EPIC-Norfolk Prospective Population Study. PLOS Med 5, 39-46. 